\title{
Assessing the taxonomic resolution of southern African trapdoor spiders (Araneae: Ctenizidae; Cyrtaucheniidae; Idiopidae) and implications for their conservation
}

Ian Engelbrecht ${ }^{1,2}$ and Lorenzo Prendini ${ }^{3}$

(1) Gauteng Department of Agriculture and Rural Development, 73 Market St., Johannesburg, South Africa

(2) Department of Zoology and Entomology, University of Pretoria, Pretoria, South Africa

(3) Division of Invertebrate Zoology, American Museum of Natural History, Central Park West at 79th Street, New York, NY 10024-5192, USA

Ian Engelbrecht (Corresponding author)

Email: ian.engelbrecht@gauteng.gov.za

Email: adustus@ananzi.co.za

Lorenzo Prendini

Email: lorenzo@amnh.org

\begin{abstract}
Taxonomic classifications simultaneously represent hypotheses of taxon identity and relationships to taxonomists, and real, unchanging entities to users of taxonomic information. Taxonomic changes, while representing scientific progress, can be a source of frustration for users. A method for assessing confidence in the taxonomy of a group of organisms would assist users of the taxonomy. A method is presented for determining the degree of development of a taxonomy, a concept termed 'taxonomic resolution'. The method was applied to six groups of southern African mygalomorph trapdoor spiders, namely Stasimopus Simon 1892 (Ctenizidae Thorell 1877), Ancylotrypa Simon 1889 (Cyrtaucheniidae Simon 1889), four genera of Idiopidae Simon 1889 assessed as a single group, Galeosoma Purcell 1903, the families Migidae Simon 1889 and Microstigmatidae Roewer 1942, and the burrowing scorpion genus Opistophthalmus C. L. Koch 1837 (Scorpionidae Latreille 1802). The method was based on the assumption that species delimitation in a group of organisms, the taxonomy of which is based on morphological characters, depends on whether the sample of material examined is adequate for assessing variation in those characters. Five assessment criteria were identified and scored for a group of species using the taxonomic literature. Estimates of the number of species remaining to be discovered and described in each group were also included in the assessment. The results obtained for the trapdoor spiders ranged from 15 to $29 \%$, indicating a potentially significant degree of uncertainty in the taxonomy. Results for Migidae and Microstigmatidae were 51 and $78 \%$ respectively, whereas the result for Opistophthalmus was $93 \%$. The applied value of a measure of taxonomic resolution, the limitations of the method, and a strategy for developing a more generally applicable method are discussed.
\end{abstract}

Keywords Mygalomorphae - Scorpiones - Systematics - Taxonomy - Species richness IUCN Red List 


\section{Introduction}

Taxonomy aims to discover, describe and name the species with which we share this planet, a fundamental scientific activity that provides the foundation for our understanding of the living world. Sound taxonomy is important for ecologists, conservationists, farmers, bioprospectors, and others (Gotelli 2004; Mace 2004; Wilson 2004). The inventory and naming of organisms that share our world documents the diversity of life on earth and facilitates communication about this diversity, which is essential for us to manage it. Taxonomy has been a fundamental discipline for over 250 years, and it is more important today than ever as human activities place increasing demands on the natural environment (Godfray and Knapp 2004).

Although taxonomy is fundamental to many scientific disciplines, changes in names and the biological entities they delimit, while representing progress in taxonomy, often frustrate the users thereof (Morrison et al. 2009). This problem arises from the dual role of names, which simultaneously represent hypotheses of identity to taxonomists, but real and assumedly unchanging entities to others (Thiele and Yeates 2002). Dayrat (2005) suggested that taxonomists should only name taxonomic entities when there is sufficient certainty in the delimitation or cohesiveness of those entities resulting from research, but that unnamed hypotheses of species identity be described in the interim. It is unlikely that the tradition of naming taxa during taxonomic research will change, however (Valdecasas et al. 2008). A method for assessing confidence in the taxonomy of a group of organisms would assist users of the taxonomy. The degree of development of a taxonomy is termed 'taxonomic resolution' for the purpose of this article, and an empirical assessment of the taxonomic resolution of several groups of southern African arachnids is presented.

The method presented was initially developed to assess the status of the taxonomy of trapdoor spiders (Ctenizidae Thorell 1887; Cyrtaucheniidae Simon 1889; Idiopidae Simon 1889) included in a systematic conservation plan for Gauteng Province, South Africa. Several species within these families were identified as being of conservation importance through an expert consultation process and included in the plan. The conservation plan protects species of conservation importance by identifying areas that should be included in a protected-area network or preventing development activities that would result in significant habitat loss where the species occur (Margules and Pressey 2000). In Gauteng Province, a heavily urbanized region where there is often conflict between development pressure and biodiversity conservation, speciesspecific conservation objectives must be well justified. A more rigorous assessment of the conservation status of trapdoor spiders was needed. Taxonomic issues became apparent when new material was collected during Environmental Impact Assessments and other survey efforts. The method presented here for indirectly assessing taxonomic resolution provides a systematic way to inform conservation status assessments when species identity might be in question.

\section{Defining 'taxonomic resolution'}

The term 'taxonomic resolution' is defined here as a measure of the degree to which a proposed taxonomic classification represents natural species (i.e. real biological entities rather than hypothetical constructs). The method presented is based on the concept that scientific theories become progressively more explanatory and predictive as research proceeds, eventually reaching 
a point where they are sufficiently comprehensive to explain both the data used in their development and new observations (Ford 2000).

This progressive theoretical development is also true for taxonomy (Lipscomb et al. 2003; Sites and Marshall 2003), where hypotheses concern the identity and limits of species, and observations are morphological or molecular characters gathered from individual specimens. Taxonomists delimit species based on these observations; for example, a species represents a group of specimens that share a unique combination of characters (Cracraft 1983; Nixon and Wheeler 1990). Further research may discover new specimens not accommodated in the original hypotheses of species identity, in which case revision may be necessary: new species may be described, species united by synonymy, the diagnoses of species expanded or restricted, and species transferred between genera. Conceptually, taxonomic research should progress to a point at which statements of species identity are sufficiently comprehensive and specific to accurately classify any new specimen not previously included in their development. The taxonomy for a group of organisms may be considered well resolved at this point. The method for assessing taxonomic resolution presented here is an attempt to assess the degree of progress towards this point.

It is important to recognize that a taxonomy is not fully resolved until all species in the group of interest have been discovered and satisfactorily described. Undescribed species must also be considered if the measure of taxonomic resolution is to indicate the likelihood of accurately identifying any specimen belonging to the group. Assessing the taxonomic resolution of a group therefore requires three steps: (1) score each described species in the group for a set of criteria identified to assess the degree of development of the taxonomy; (2) estimate the number of undescribed species awaiting discovery in the group; (3) calculate the taxonomic resolution of the group using the metrics obtained from the preceding steps.

Finally, the term taxonomic resolution as used here should not be confused with phylogenetic resolution, which indicates the level of understanding of relationships between species or other taxa (e.g. Miller 2003), or the Linnean rank to which specimens are identified in datasets of community composition (also termed taxonomic resolution, e.g. Anderson et al. 2005; Chessman et al. 2007; Jones 2008).

\section{Methods}

\section{Focal taxa}

The taxonomic resolution of all trapdoor spider genera included in the Gauteng Province conservation plan was assessed. Stasimopus Simon 1892 (Ctenizidae), Ancylotrypa Simon 1889 (Cyrtaucheniidae) and Galeosoma Purcell 1903 (Idiopidae) were assessed at the genus level. The idiopid genera Ctenolophus Purcell 1904, Idiops Perty 1833, Segregara Tucker 1917 and Gorgyrella Purcell 1902 were assessed as a single group as it is uncertain whether these genera are monophyletic as currently defined (Hewitt 1919a; Raven 1985). Galeosoma, Stasimopus and Ancylotrypa, considered sufficiently distinctive morphologically to be readily diagnosable, were assessed as individual groups. All species within the abovementioned genera occurring in the southern African countries of Botswana, Lesotho, Mozambique, Namibia, South Africa, Swaziland and Zimbabwe were included in the assessment. 
Assessments were also undertaken for the southern African species of the mygalomorph spider families Migidae Simon 1889 and Microstigmatidae Roewer 1942, both revised fairly recently (Griswold 1985, 1987a, b), and the southern African burrowing scorpions of the genus Opistophthalmus C. L. Koch 1837 (Scorpionidae Latreille 1802), currently under revision by the second author.

The taxonomic literature required to assess Stasimopus, Ancylotrypa, Galeosoma and the other idiopid genera was identified using the Catalogue of Spiders of the World (Platnick 2008). As many relevant publications were obtained as possible. The following references were consulted: Pocock (1897, 1898a, b, 1900, 1901, 1902a, b), Purcell (1902, 1903a, b, 1904, 1908), Hewitt (1910, 1913a, b, 1914, 1915a, b, c, d, 1916, 1917, 1919a, b, 1923, 1925, 1927, 1934, 1935), Strand (1906, 1907, 1917), Tucker $(1917,1920)$, Lawrence $(1927,1937)$ and Hendixson and Bond (2004).

In most cases, authors would describe or redescribe species from several higher taxa in the same publication. Original and supplementary descriptions were collated for each species and considered together in the assessment. Intraspecific taxa (subspecies and varieties) were treated as equivalent to species. Each species was individually scored for the criteria described below. Scoring involved reading through the collated literature for each species in chronological order, finding the relevant information, and capturing the scores for the criteria described below for each species in a matrix.

\section{Assessing described species}

The current taxonomy of southern African trapdoor spiders is based on characters of the external morphology. Species delimitation is typically based on identifying discontinuities in the variation of characters among populations, which requires samples of specimens that are sufficiently representative of the variation among and within populations. The method presented aims to assess taxonomic resolution indirectly by quantifying whether the sample of material examined for a species description is adequate for identifying such discontinuities. Five criteria were identified for doing so.

\section{Criterion 1. Adult male specimens were described}

Many arachnid species are markedly sexually dimorphic and, in some cases, diagnostic characters may only be present in one sex, usually the adult male (Hewitt 1915a; Tucker 1917; Prendini 2001). Examples include the tibial spurs and palpal mating organs of male mygalomorph spiders, the cheliceral flagellum of male solifuges, and the hemispermatophore and secondary sexual characters of male scorpions (Raven 1985; Polis and Sissom 1990; Punzo 1998). Conspecific males and females of markedly sexually dimorphic taxa, like trapdoor spiders, may be described as different species if discovered at different times or in different localities. Conversely, heterospecific males and females may be described as the same species when the description is based on single sex samples from different localities. In general, more certainty can be placed in descriptions of arachnid species in which the adult male is known than in those based only on adult females or immature stages. Consequently, this criterion received the highest weighting in the assessment. 
Criterion 2. Adult female specimens were described

Most taxonomically informative, diagnostic morphological characters of arachnids occur only in the adult stage. Ontogenetic variation in many characters used to describe arachnids causes significant uncertainty when species are delimited on the basis of immature specimens only (see e.g. Raven 1985; Prendini 2001). Although adult males are usually essential for delimiting species, adult females may provide additional diagnostic characters not present in the immature stages. This criterion therefore allowed species described only from adult females to score higher than those described only from immatures.

\section{Criterion 3. Samples from at least one locality permitted adequate assessment of variation}

It is important that sample sizes be adequate for assessment of intraspecific variation and identification of consistent, diagnostic character states for species delimitation. Very large sample sizes may be required to obtain high statistical confidence that a particular morphological character state is fixed for a particular species (Wiens and Servedio 2000) but in many cases taxonomists make accurate decisions about species limits using samples of a few individuals and expert knowledge of the group. Delimiting species on the basis of very small samples or single specimens may be tenuous, however, especially among very closely related and morphologically similar (cryptic) species. In the present assessment, a threshold of three specimens in a single sample was set for assessment of intraspecific variation as this would enable a modest assessment of variation by a taxonomist without placing unrealistic expectations on the quantity of specimens available for study. Statistical power analysis can be used to determine minimum sample sizes needed to delimit species using quantitative characters (but this still requires the potentially arbitrary specification of a threshold) and presents an opportunity to refine the method for application to other taxa. In scoring this criterion, only one sample was required to meet the threshold and the specimens had to be of the same sex.

\section{Criterion 4. Sufficient samples were available to assess geographical variation}

In addition to adequately assessing the variation among specimens from a single population, species delimitation must consider the variation among specimens from different populations. When sample sizes are small, geographical variation may be misinterpreted as diagnostic and mistakenly used as the basis for species delimitation. For example, specimens from localities at the extremes of a cline may be misinterpreted to represent different species if no material is observed from intervening localities. In such cases, the delimitation of these species is an artifact of poor geographical sampling. Thus, delimitation of species based on samples from multiple allopatric populations is a positive attribute of a taxonomy. Localities were used as a proxy for populations for this criterion. A threshold of three samples from different geographical localities was set, for the same reasons as in Criterion 4. The number of specimens in each sample was not considered.

\section{Criterion 5. No uncertainty in delimitation was stated or implied}

In many old descriptions examined during the assessment, authors indicated uncertainty about the validity of particular species. Such uncertainty was factored into the assessment using this 
criterion. The expert knowledge of the revising author for the burrowing scorpions indicated where uncertainty remains in species limits for this group.

The abovementioned criteria were scored 'true' or 'false' for each species within each group under consideration using the taxonomic literature described earlier. In obtaining a score for each species, two points were awarded when Criterion 1 was assessed to be 'true' and one point awarded when each of the other criteria was assessed to be 'true'. Zero points were awarded when a criterion was assessed to be 'false'. Weighting Criterion 1 in this way ensured that species in which both sexes were described, scored higher than those described only from adult males, which in turn scored higher than those described only from adult females, which in turn scored higher than those described only from immatures. The total score for a species is the sum of points awarded for all criteria.

\section{Estimating undescribed species}

Several approaches exist for estimating the total richness of a species community, be it over a geographical region, landscape or single sample plot, and these may be extended to estimating species richness within taxa. These methods include the use of taxon ratios (Hammond 1994; Colwell and Coddington 1994), parametric model-fitting to species accumulation curves and non-parametric species richness estimation methods (Colwell and Coddington 1994; Chao 2005), species detection probability methods, based on mark/recapture models using temporally or spatially replicated samples (MacKenzie et al. 2002, 2005), and methods based on spatial turnover of species (Harte et al. 1999; Ugland et al. 2003; Jobe 2008). Accumulation curve model-fitting and non-parametric estimation are most often used, and several models and estimators are available. The data required for these methods are either a matrix of species presence and absence over several sample plots, or species identifications of individual specimens recorded randomly from a community (Gotelli and Colwell 2001).

Non-parametric methods, based on the ratio of singletons (species recorded once) and doubletons (species recorded twice) to the total number of species, were used to estimate species richness for the taxa of interest in the present assessment. Species occurrence data obtained from the taxonomic literature for mygalomorph spiders and a comprehensive database of specimen records for Opistophthalmus were used to develop the datasets needed for the estimates. Samples were recorded as species occurrences at individual localities, as opposed to using collection events or individual specimens, as it is expected that most new species will be discovered at previously unsampled localities. Locality names for the mygalomorph spiders were standardised so that permutations of the same name in the literature would represent a single sample in the dataset. This resulted in 50 records for Ancylotrypa, 94 for Stasimopus, 48 for Galeosoma, and 102 for the other idiopid genera. The original dataset for Opistophthalmus comprised approximately 3500 unique locality names and 4300 species records. It was difficult to standardise locality names for this dataset because it was not always apparent whether different records were sufficiently separated to be considered different localities using the names alone. The number of singleton and doubleton species was therefore determined by plotting species records in a GIS (ArcGIS 9.3) and examining the geographical distribution of records for each species. Records less than $2 \mathrm{~km}$ apart were treated as a single locality. In most cases, singleton 
and doubleton species with multiple locality records were readily apparent as the records were closely clustered.

Richness estimates were calculated for the mygalomorph spiders with the software package EstimateS Version 8.20 (Colwell 2009). The Chao 2 estimator was chosen as it uses incidence data (i.e. species presence/absence per locality or sample), producing estimates considered reasonable given our expert knowledge of the taxa involved, and confidence limits that in most cases encompassed estimates obtained with other estimators. The exception was Microstigmatidae, where Chao 2 estimated that no new species remain to be discovered, whereas several other estimators indicated the possibility of one or two undescribed species. Richness estimates were obtained manually for Opistophthalmus using the same formulas for Chao 2 implemented in EstimateS (Colwell 2009).

Several other studies used museum records or data drawn from the taxonomic literature for richness estimation (e.g. Meier and Dikow 2004; Jones et al. 2009; Petersen et al. 2003; Petersen and Meier 2003; Beck and Kitching 2007; Guralnick and Van Cleve 2005), but the most appropriate methods, given the idiosyncracies of such data, need further investigation. Until then, the choice of estimators and interpretation of results will remain a matter of expert evaluation (Petersen and Meier 2003; Petersen et al. 2003; Beck and Kitching 2007).

Calculating taxonomic resolution

Overall taxonomic resolution scores were calculated for each group assessed using the following formula, where $s=$ the score for each species obtained by applying the assessment criteria, $n=$ the total number of species estimated for the taxon, and $z=$ the highest score that could be obtained using the assessment criteria (in this case, six):

$$
\sum s /(n * z)
$$

Calculated as such, the score for each described species contributes to a cumulative score for the taxon being assessed. Undescribed species effectively contribute scores of zero. If every species within the group scored 'true' for all five criteria, and all species had been discovered, the overall score would be 1 or $100 \%$. The taxonomic resolution estimate was calculated using means and $95 \%$ confidence limits for species richness estimates substituted for $n$.

\section{Results}

Taxonomic resolution estimates were 26\% for Stasimopus, 15\% for Ancylotrypa, 29\% for Galeosoma, 20\% for the other idiopid genera, 51\% for Migidae, 78\% for Microstigmatidae and 93\% for Opistophthalmus (Table 1). The estimates obtained for the migids, microstigmatids and Opistophthalmus were generally higher than those for the other groups. Mean and 95\% confidence limits for the number of undescribed species were 41 (15-108) for Stasimopus, 72 (22-233) for Ancylotrypa, 11 (2-52) for Galeosoma, 61 (24-152) for the other idiopid genera, 8 (2-38) for the Migidae, zero for Microstigmatidae and 2 (0-44) for Opistophthalmus. Fewer undescribed species resulted in higher taxonomic resolution estimates as there were fewer species contributing a score of zero to the overall score for the taxon, whereas the upper richness estimates resulted in more species contributing a score of zero and a lower taxonomic resolution estimate. The large upper estimates of the number of undescribed species of Ancylotrypa and Galeosoma resulted from the relatively small sample sizes for these groups and are probably 
unrealistic. The mean and lower estimates, and their corresponding taxonomic resolution estimates, appear reasonable.

Table 1 Taxonomic resolution assessment of southern Africa trapdoor spider genera Ancylotrypa Simon 1889, Galeosoma Purcell 1903, Stasimopus Simon 1892, four other idiopid genera (Ctenolophus Purcell 1904, Gorgyrella Purcell 1902, Idiops Perty 1833, and Segregara Tucker 1917), the mygalomorph families Migidae Simon 1889 and Microstigmatidae Roewer 1942, and the burrowing scorpion genus Opistophthalmus C. L. Koch 1837

\begin{tabular}{|c|c|c|c|c|c|c|c|c|c|c|}
\hline & $\mid$\begin{tabular}{|l} 
Species \\
include \\
d in \\
assess \\
ment
\end{tabular} & $\mid$\begin{tabular}{|l} 
Descri \\
bed \\
from \\
adults \\
of \\
both \\
sexes \\
$(\%)$
\end{tabular} & $\mid \begin{array}{l}\text { Descri } \\
\text { bed } \\
\text { from } \\
\text { adult } \\
\text { males } \\
\text { only } \\
(\%)\end{array}$ & $\mid$\begin{tabular}{|l} 
Descri \\
bed \\
from \\
adult \\
female \\
s only \\
(\%)
\end{tabular} & \begin{tabular}{|l} 
Within \\
- \\
popula \\
tion \\
variati \\
on \\
assesse \\
d (\%)
\end{tabular} & $\mid$\begin{tabular}{|l} 
Amon \\
g- \\
popula \\
tion \\
variati \\
on \\
assesse \\
d (\%)
\end{tabular} & $\begin{array}{l}\text { No } \\
\text { uncertai } \\
\text { nties } \\
\text { stated } \\
(\%)\end{array}$ & $\mid$\begin{tabular}{|l} 
Specie \\
s \\
estim \\
ated \\
to \\
exist
\end{tabular} & \begin{tabular}{|l} 
Estim \\
ated \\
specie \\
s \\
alread \\
y \\
descri \\
bed \\
$(\%)$ \\
\end{tabular} & \begin{tabular}{|l} 
Taxon \\
omic \\
resolut \\
ion \\
estimat \\
e (\%)
\end{tabular} \\
\hline Ancylotryp & $\mid$ || 31 & || 42 & 26 & $\mid 29$ & $\mid 16$ & $\mid 10$ & 87 & {$\left[\begin{array}{l}102 \\
(52- \\
263)\end{array}\right.$} & \begin{tabular}{|l|}
29 \\
$(11-$ \\
$58)$ \\
\end{tabular} & $\mid \begin{array}{l}15(6- \\
30)\end{array}$ \\
\hline $\begin{array}{l}\text { Idiopid } \\
\text { genera }\end{array}$ & ||49 & $\mid 33$ & $\mid 20$ & $\mid 43$ & $\mid 8$ & $\mid 2$ & 27 & $\begin{array}{l}121 \\
(77- \\
233)\end{array}$ & \begin{tabular}{|l}
42 \\
$(22-$ \\
$66)$ \\
\end{tabular} & $\mid \begin{array}{l}20(10- \\
31)\end{array}$ \\
\hline Stasimopus & ||42 & || 48 & $\| 14$ & $\mid 38$ & $\mid 10$ & ||7 & 22 & $\begin{array}{l}84 \\
(58- \\
151)\end{array}$ & \begin{tabular}{|l}
52 \\
$(28-$ \\
$76)$
\end{tabular} & $\begin{array}{l}26(14- \\
39)\end{array}$ \\
\hline Galeosoma & $\mid 15$ & || 13 & $\mid 0$ & $\mid 80$ & $\mid 53$ & || 27 & 93 & \begin{tabular}{|l}
26 \\
$(17-$ \\
$67)$
\end{tabular} & \begin{tabular}{|l|}
58 \\
$(22-$ \\
$87)$ \\
\end{tabular} & $\mid \begin{array}{l}29(11- \\
43)\end{array}$ \\
\hline Migidae & $\mid 25$ & $\mid 36$ & $\mid 8$ & $\mid 56$ & |68 & $\mid 52$ & 100 & $\begin{array}{l}33 \\
(27- \\
63)\end{array}$ & \begin{tabular}{|l}
76 \\
$(40-$ \\
$94)$ \\
\end{tabular} & $\mid \begin{array}{l}51(27- \\
62)\end{array}$ \\
\hline $\begin{array}{l}\text { Microstigm } \\
\text { atidae }\end{array}$ & $\mid 6$ & $\mid 83$ & 0 & || 17 & $\mid 67$ & || 33 & 100 & $\mid 6$ & $\mid 100$ & 78 \\
\hline $\begin{array}{l}\text { Opistophth } \\
\text { almus }\end{array}$ & || 130 & $\mid 98$ & $\mid 2$ & $\| 0$ & $\mid 87$ & || 79 & 90 & $\mid \begin{array}{l}132 \\
(130- \\
174)\end{array}$ & $\begin{array}{l}98 \\
(75- \\
100)\end{array}$ & $\mid \begin{array}{l}93(71- \\
95)\end{array}$ \\
\hline
\end{tabular}

Within individual groups, Stasimopus spinosus Hewitt 1914 scored six whereas S. artifex Pocock 1902 scored one, with most other Stasimopus species (38\%) scoring two. Ancylotrypa nuda (Hewitt 1916) and A. pretoriae (Hewitt 1913) scored six whereas A. granulata (Hewitt 1935), A. coloniae (Pocock 1902) and A. elongata Purcell 1908 scored one. The majority of other Ancylotrypa species (58\%) scored three or four. Galeosoma pallidum pilosum Hewitt 1916 and G. vandami Hewitt 1915 scored six whereas G. vandami circumconjunctum Hewitt 1919 and G. 


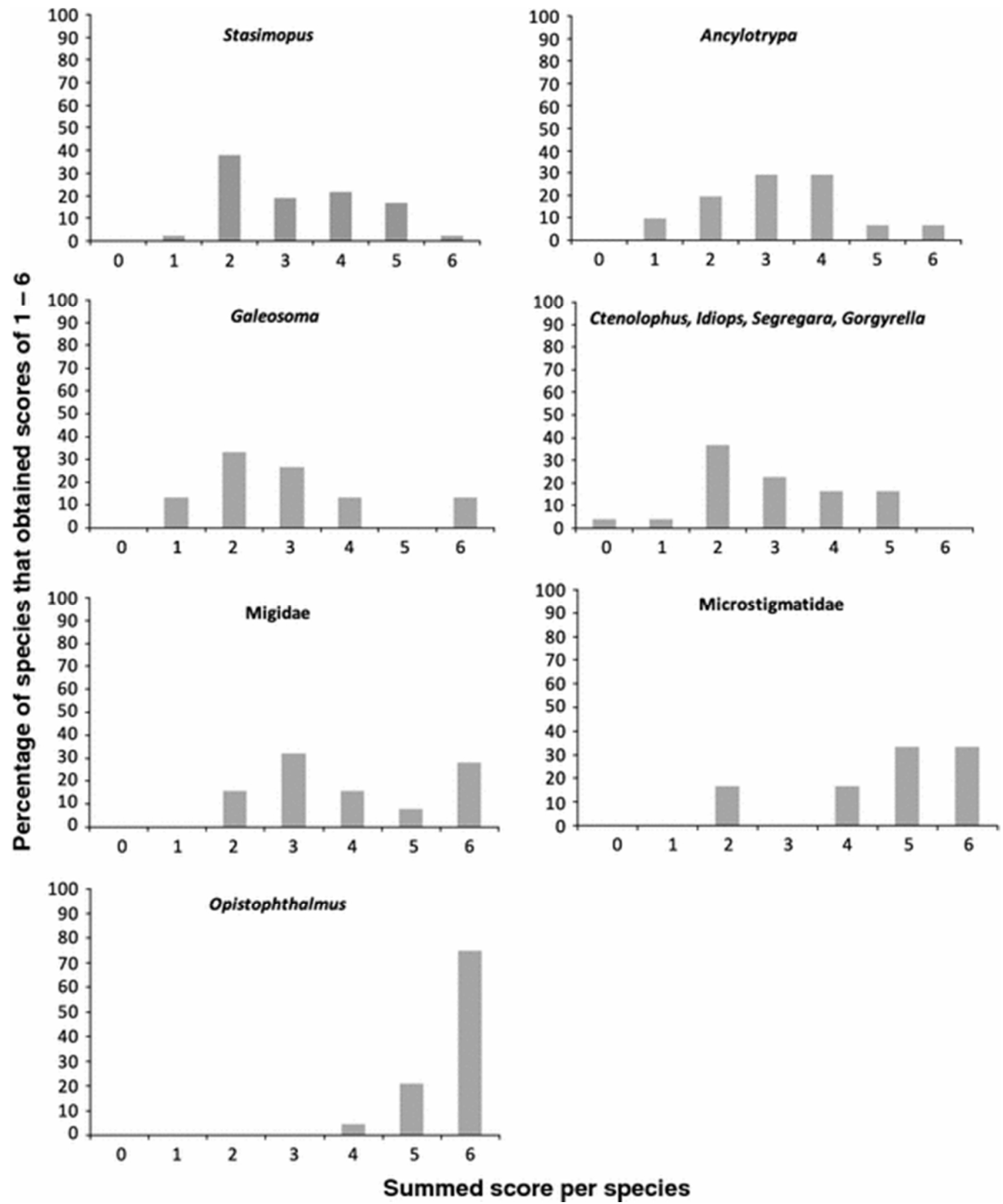

Fig. 1 Percentage of species that scored zero to six in taxonomic resolution assessment of southern Africa trapdoor spider genera Ancylotrypa Simon 1889, Galeosoma Purcell 1903, Stasimopus Simon 1892, four other idiopid genera (Ctenolophus Purcell 1904, Gorgyrella Purcell 1902, Idiops Perty 1833, and Segregara Tucker 1917), the mygalomorph families Migidae Simon 1889 and Microstigmatidae Roewer 1942, and the burrowing scorpion genus Opistophthalmus C. L. Koch 1837

crinitum Hewitt 1919 scored one, with most other Galeosoma species scoring two or three (33 and $27 \%$ respectively). Among the other idiopid genera, no species scored six, Idiops grandis (Hewitt 1915) and I. pulcher Hewitt 1914 scored one, I. castaneus Hewitt 1913 and I. striatipes 
Purcell 1908 scored zero, with most other species (37\%) scoring two. No migids or microstigmatids scored zero or one. Seven migid species $(28 \%)$ scored six, whereas most microstigmatids (67\%) scored five or six. No species of Opistophthalmus scored zero or one and the majority of species (75\%) scored six. The percentage of species in each group that scored zero to six is presented in Fig. 1.

\section{Discussion}

\section{Trapdoor spider taxonomy}

The results of this analysis indicate that the taxonomy of southern African trapdoor spiders is poorly resolved. This finding was expected as most of the species were described in the early 1900s before modern standards and methods had been established, and when opportunities to travel and collect were limited. The higher taxonomic resolution estimates obtained for migids, microstigmatids and Opistophthalmus were also expected, given the more recent work on these groups. The scores obtained for migids and microstigmatids were limited to some extent by the small sample sizes available. The migids obtained a mean estimate of $51 \%$ with the lower confidence limit comparable to the results obtained for the low-scoring groups. The high estimate for Opistophthalmus is attributed to the large number of specimens examined from a wide range of localities. These results indicate that the resolution of a taxonomy is not simply a function of whether or not the taxon has been revised. Revisions of different groups may resolve their taxonomy to differing degrees, but will always be constrained by the availability of sufficient material for determining species boundaries. This is an important consideration for trapdoor spiders. The cryptic nature of these animals makes obtaining additional material difficult and small samples are likely to remain a limiting factor for modern revisions. Future work should focus on collecting more material, with particular emphasis on obtaining both sexes of described species and larger samples from individual localities. Resampling type localities should be a priority. As sampling these animals is costly, additional sampling localities should be carefully chosen to obtain maximum coverage of the environmental conditions and geographic extent of the region with available resources (Hirzel and Guisan 2002; Hortal and Lobo 2005).

The scores obtained for individual species during the assessment process can also provide useful information, indicating which species are relatively poorly sampled, or the limits of which appear to be less defined, compared to those which are relatively better sampled or the limits of which are better defined. However, scores for individual species should be interpreted in light of scores obtained for the group as a whole. For example, two species of Galeosoma, G. pallidum pilosum and G. vandami, obtained high individual scores, but the overall estimate for Galeosoma $(29 \%)$ was fairly low. Hewitt (1916) noted the similarities between G. pilosum and G. pallidum, and later reduced it to a subspecies of the latter (Hewitt 1935). Adult males collected near the type localities of G. pallidum pilosum, G. pallidum and G. hirsutum also suggest these taxa are potentially synonymous (I. Engelbrecht, pers. obs.). Therefore, species with high scores in groups with low overall taxonomic resolution should not necessarily be regarded as wellresolved species. Conversely, species with low individual scores, such as those known from single specimens, may be so distinctive that there is no question about their validity.

Poorly resolved trapdoor spider taxonomy will likely result in misidentifications of undescribed species, poorly resolved species, and undescribed sexes of species known from only one sex. 
Users of the taxonomy should be aware of these potential pitfalls. Matching specimens with descriptions and identifying specimens using keys based on a poorly resolved taxonomy will often lead to misidentifications. In the absence of taxonomic revisions and reliable keys, identifying trapdoor spiders will require individuals to develop their expert knowledge by examining types and other material as well as familiarizing themselves with the literature. Uncertain identifications and methods of identification should be indicated on specimen determination labels.

\section{Conservation implications}

The results of this study provided invaluable information for assessing the conservation status of the trapdoor spiders included in the Gauteng conservation plan. Rigorous conservation assessments are difficult when taxonomic questions exist as the uncertainty is propagated to the population or distributional data available. In such cases, a Data Deficient listing is appropriate (IUCN 2010). Importantly, the conservation status of a species must be considered with other factors, such as degree of threat and cost of remediation, when determining appropriate conservation action (Possingham et al. 2002). In Gauteng Province, where development pressure is severe, precautionary conservation action may be warranted for trapdoor spiders until further research indicates otherwise.

This study demonstrates the value of estimates of taxonomic resolution for a particular group of animals. The method presented is simple to understand and implement using the taxonomic literature, and provides a measure of confidence in the taxonomy of a group of organisms. Its primary shortcoming is that the assessment criteria used are not generally applicable to a broad range of taxa as they do not consider sources of evidence used in species delimitation other than morphological characters. It would not be difficult to adapt or augment the criteria for other taxa, however. The method is only an indirect assessment of taxonomic resolution, but a more rigorous analysis is not possible with the data provided in the taxonomic literature of most organisms. Additionally, the method does not consider more complex aspects of the taxonomic process, such as synonymy (Gaston and Mound 1993; Solow et al. 1995), nor does it consider expert knowledge or the application of different taxonomic concepts (i.e. species definitions) by different taxonomists. These factors contribute to its simplicity, but important information might not be captured in the estimate obtained from such an assessment. Further development of approaches for assessing taxonomic resolution is required so that other scientific disciplines and endeavors may consider this information explicitly.

\section{Future directions}

How should a more generally applicable approach for assessing taxonomic resolution be developed? The primary challenge is to develop a method that is applicable to the broad range of character systems used in taxonomy while remaining relatively easy to apply. The method presented here was developed specifically for a group of organisms in which the primary characters for species delimitation are discrete, qualitative or meristic attributes of external morphology. Eye arrangement, leg measurement ratios, spination patterns, and the development of modifications to the appendages, particularly in adult males, are the primary character systems available for trapdoor spiders. As such character systems often exhibit a fairly broad range of 
intraspecific variation, large sample sizes are important for species delimitation. This may be contrasted with the situation in araneomorph spiders and most insects, in which the complex, species-specific reproductive structures primarily used for species delimitation exhibit little intraspecific variation, allowing species to be delimited with confidence on the basis of one or a few specimens (but see Huber 2003 for critique). In such cases, two of the five criteria developed for the present assessment are rendered inapplicable, although some uncertainty may remain in matching conspecific males and females. Various other sources of data exist for species delimitation, including behavioural differences (e.g. call sonograms in birds, frogs and bats), ecological differences illustrated by field data or ecological niche models, differences in phenology, chromosomes, etc. Molecular data also represent a significant source of data, often used in conjunction with others. Integration of these diverse sources into a single assessment of taxonomic resolution will be more challenging but not impossible.

The IUCN Red List (IUCN 2001) approach to assessing the extinction risk of species may offer a conceptual model for further development of approaches to assessing taxonomic resolution. The history of the Red List criteria and approaches to their development are outlined by Mace et al. (2008). The current criteria are applicable to a broad range of taxa and make use of data that are readily available for many taxa, i.e. population sizes, changes to population size and extent of distributional ranges. Sets of criteria were developed for particular groups, such as birds, and later merged and refined to produce the current set of generally applicable criteria.

Mace et al. (2008) make the important point that the Red List criteria do not attempt to determine the extinction risk of a species as a function of the specific threats to which it is exposed, but rather to determine the extinction risk from a generic set of symptoms that arise as a result of those threats. The intention is not to identify details about threats during the assessment process, but to broadly identify species for which further investigation and potential remediation might be required. A similar approach to developing a generic set of criteria for assessing taxonomic resolution would require assessing the symptoms of taxonomies with differing degrees of resolution. For example, poorly resolved taxonomies are likely to be unstable, resulting in many misidentified specimens and rapidly changing species boundaries, relative to the number of taxonomic publications. These symptoms are not simple to identify or assess, however. In following the Red List model, a starting point might be to develop taxon-specific methods for assessing taxonomic resolution and, once sufficient progress has been made, initiating attempts to synthesize those into a generally applicable framework.

The question remains as to the importance of assessing the taxonomic resolution for a group of organisms. This depends on the costs associated with the application of a taxonomy. When costs are high, as was the case when trapdoor spider conservation objectives conflicted with urban development objectives in Gauteng Province, understanding the degree of development of the taxonomy is important. These spiders were included in the conservation plan on the grounds that their poor representation in museum collections indicated rarity, and urban development had been extensive in the areas where they were known to occur. This precautionary approach was justified given the data available, but the outcome may have differed if the estimates of taxonomic resolution presented here had been available. Other examples in which taxonomic resolution is potentially important include bioprospecting organisms for potential pharmacological properties or as biological control agents, assessing the invasiveness of alien 
species, plant pathogen identification and control, or in any other field of applied biology that relies fundamentally on taxonomy.

Lastly, a measure of taxonomic resolution would be useful for the taxonomic process itself. Measures of taxonomic resolution may be used to prioritise taxonomic research on groups for which a well resolved taxonomy is important, or to evaluate alternative taxonomies for the same group of organisms. Taxonomic resolution could be used to demonstrate the value of specific taxonomic works produced by individuals or the cumulative improvement in the taxonomy of a group of organisms resulting from the work of a specific project or research team over a period of time. This would be valuable in justifying continued funding and research. The assessment of taxonomic resolution in preparation for a taxonomic revision would also indicate areas to which attention should be focused during the revisionary process, and those that would achieve the greatest advances to the taxonomy. For example, a substantial improvement in the taxonomic resolution of Galeosoma could be made by the discovery and description of adult males, known in only two of the fifteen described species and subspecies, compared to females, which are relatively well sampled in most species. Thus, further sampling, using methods suited for obtaining adult males, should be prioritised for future revision of this group.

\section{Conclusion}

The concept and utility of a measure of the degree of resolution of a taxonomy has been demonstrated for several groups of southern African arachnids. Conservation assessments should include an assessment of the taxonomic status of species under consideration, particularly where comprehensive taxonomic revisions have not been undertaken, and this approach provides a systematic method of doing so. The measure is applicable to arachnids (and other invertebrates), the taxonomy of which is based on external morphology. More generally applicable, integrative measures will require further development.

Acknowledgments The following people are graciously acknowledged for supplying taxonomic literature for trapdoor spiders: Ansie Dippenaar-Schoeman of the Agricultural Research Council, Plant Protection Research Institute, Pretoria; Tersia Peregil of the Transvaal Museum, Pretoria; and Sadeck Casoojee of the South African Museum, Cape Town. Gavin Masterson, Siyabonga Buthelezi and six anonymous referees are thanked for their comments and suggestions on the manuscript. Lorenzo Prendini was supported by National Science Foundation DEB grants 0228699 and 0413453.

\section{References}

Anderson MJ, Connel SD, Gillanders BM, Diebel CE, Blom WM, Saunders JE, Todd JL (2005)

Relationships between taxonomic resolution and spatial scales of multivariate variation. J Anim Ecol 74:636-646

Beck J, Kitching IJ (2007) Estimating regional species richness of tropical insects from museum data: a comparison of geography-based and museum-based methods. J Appl Ecol 44:672-681

Chao A (2005) Species estimation and applications. In: Balakrishnan N, Read CB, Vidakovic B (eds) Encyclopedia of statistical sciences. Wiley, New York, pp 7907-7916 
Chessman B, Williams S, Besley C (2007) Bioassessment of streams with macroinvertebrates: effect of sampled habitat and taxonomic resolution. J N Am Benthol Soc 26(3):546-565

Colwell RK (2009) EstimateS: statistical estimation of species richness and shared species from samples. Version 8.2. User's guide and application published at: http://purl.oclc.org/estimates. Accessed 22 June 2010

Colwell RK, Coddington JA (1994) Estimating terrestrial biodiversity through extrapolation. Phil Trans R Soc Lond B 345:101-118

Cracraft J (1983) Species concepts and speciation analysis. Curr Ornithol 1:159-187

Dayrat B (2005) Towards integrative taxonomy. Biol J Linn Soc 85:407-415

Ford ED (2000) Scientific method for ecological research. Cambridge University Press, Cambridge

Gaston KJ, Mound MA (1993) Taxonomy, hypothesis testing and the biodiversity crisis. Proc R Soc Lond B 251:139-142

Godfray HCJ, Knapp S (2004) Introduction: taxonomy in the 21st century. Phil Trans R Soc Lond B 359:559-569

Gotelli NJ (2004) A taxonomic wishlist for community ecology. Phil Trans R Soc Lond B 359:585-597

Gotelli NJ, Colwell RK (2001) Quantifying biodiversity: procedures and pitfalls in the measurement and comparison of species richness. Ecol Lett 4:279-391

Griswold CE (1985) A revision of the African spiders of the family Microstigmatidae (Araneae: Mygalomorphae). Ann Natal Mus 27(1):1-37

Griswold CE (1987a) The African members of the trap-door spider family Migidae (Araneae: Mygalomorphae) 1: the genus Moggridgea O. P. Cambridge, 1875. Ann Natal Mus 28(1):1-118

Griswold CE (1987b) The African members of the trap-door spider family Migidae (Araneae: Mygalomorphae) 2: the genus Poecilomigas Simon 1903. Ann Natal Mus 28(2):475-497

Guralnick R, Van Cleve J (2005) Strengths and weaknesses of museum and national survey datasets for predicting regional species richness: comparative and combined approaches. Divers Distrib 11:349-359 
Hammond PM (1994) Practical approaches to the estimation of the extent of biodiversity in speciose groups. Phil Trans R Soc Lond B 345:119-136

Harte J, McCarthy S, Taylor K et al (1999) Estimating species-area relationships from plot to landscape scale using species spatial turnover data. Oikos 86(1):45-54

Hendixson BE, Bond JE (2004) A new species of Stasimopus from the Eastern Cape Province of South Africa (Araneae, Mygalomorphae, Ctenizidae), with notes on its natural history. Zootaxa 619:1-14

Hewitt J (1910) Description of two trapdoor spiders from Pretoria (female of Acanthodon pretoriae Poc. and Stasimopus robertsi, n. sp.). Ann Transvaal Mus 2:74-76

Hewitt J (1913a) Descriptions of new and little known species of trapdoor spiders (Ctenizidae and Migidae) from South Africa. Rec Albany Mus 2:404-434

Hewitt J (1913b) Descriptions of new species of Arachnida from Cape Colony. Rec Albany Mus 2:462481

Hewitt J (1914) Descriptions of new Arachnida from South Africa. Rec Albany Mus 3:1-37

Hewitt J (1915a) Descriptions of new South African Arachnida. Rec Albany Mus 3:70-106

Hewitt J (1915b) Descriptions of several new or rare species of Araneae from the Transvaal and neighborhood. Ann Transvaal Mus 5:89-100

Hewitt J (1915c) New South African Arachnida. Ann Natal Mus 3:289-327

Hewitt J (1915d) Notes on several four-lunged spiders in the collection of the Durban Museum, with descriptions of two new forms. Ann Durban Mus 1:125-133

Hewitt J (1916) Descriptions of new South African spiders. Ann Transvaal Mus 5:180-213

Hewitt J (1917) Descriptions of new South African Arachnida. Ann Natal Mus 3:687-711

Hewitt J (1919a) Descriptions of new South African Araneae and Solifugae. Ann Transvaal Mus 6:63111

Hewitt J (1919b) Descriptions of new South African spiders and a solifuge of the genus Chelypus. Rec Albany Mus 3:196-215

Hewitt J (1923) On certain South African Arachnida, with descriptions of three new species. Ann Natal Mus 5:55-66

Hewitt J (1925) Descriptions of some African Arachnida. Rec Albany Mus 3:277-299

Hewitt J (1927) On some new arachnids from South Africa. Rec Albany Mus 3:416-429 
Hewitt J (1934) On several solifuges, scorpions and a trapdoor spider from South West Africa. Ann Transvaal Mus 15:401-412

Hewitt J (1935) Scientific results of the Vernay-Lang Kalahari Expedition, March to September 1930. The trap-door spiders, scorpions and solifuges. Ann Transvaal Mus 16:459-479

Hirzel A, Guisan A (2002) Which is the optimal sampling strategy for habitat suitability modeling? Ecol Modell 157:331-341

Hortal J, Lobo JM (2005) An ED-based protocol for optimal sampling of biodiversity. Biodivers Conserv $14: 2913-2947$

Huber BA (2003) Rapid evolution and species specificity of arthropod genitalia: fact or artifact? Org Divers Evol 3:63-71

IUCN (2001) IUCN Red List categories and criteria: version 3.1. IUCN Species Survival Commission. IUCN, Gland

IUCN (2010) Guidelines for using the IUCN categories and criteria Version 8.0. IUCN Standards and Petitions Subcommittee. http://intranet.iucn.org/webfiles/doc/SSC/RedList/RedListGuidelines.pdf

Jobe RT (2008) Estimating landscape scale species richness: reconciling frequency- and turnover-based approaches. Ecology 89(1):174-182

Jones FC (2008) Taxonomic sufficiency: the influence of taxonomic resolution on freshwater bioassessments using benthic macroinvertebrates. Environ Rev 16(1):45-69

Jones OR, Purvis A, Baumgardt E et al (2009) Using taxonomic revision data to estimate the geographic and taxonomic distribution of undescribed species richness in the Braconidae (Hymenoptera, Ichneumonoidea). Insect Conserv Divers 2:204-212

Lawrence RF (1927) Contributions to a knowledge of the fauna of South-West Africa. V. Arachnida. Ann S Afr Mus 25(1):1-75

Lawrence RF (1937) A collection of Arachnida from Zululand. Ann Natal Mus 8:211-273

Lipscomb D, Platnick N, Wheeler Q (2003) The intellectual content of taxonomy: a comment on DNA taxonomy. Trends Ecol Evol 18(2):65-66

Mace GM (2004) The role of taxonomy in species conservation. Phil Trans R Soc Lond B 359:711-719 
Mace GM, Collar NJ, Gaston KJ et al (2008) Quantification of extinction risk: IUCN's system for classifying threatened species. Conserv Biol 22(6):1424-1442

MacKenzie DI, Nichols JD, Lachman GB et al (2002) Estimating site occupancy rates when detection probability is less than one. Ecology 83(8):2248-2255

MacKenzie DI, Nichols JD, Sutton N et al (2005) Improving inferences in population studies of rare species that are detected imperfectly. Ecology 86(5):1101-1113

Margules CR, Pressey RL (2000) Systematic conservation planning. Nature 405:243-253

Meier R, Dikow T (2004) Significance of specimen databases from taxonomic revisions for estimating and mapping global species diversity of invertebrates and for repatriating reliable specimen data. Conserv Biol 18(2):478-488

Mller JA (2003) Assessing progress in systematics with continuous jackknife function analysis. Syst Biol 52(1):55-65

Morrison WR, Lohr JL, Duchen P et al (2009) The impact of taxonomic change on conservation: does it kill, can it save, or is it just irrelevant? Biol Conserv 142:3201-3206

Nixon KC, Wheeler QD (1990) An amplification of the phylogenetic species concept. Cladistics 6:211223

Petersen FT, Meier R (2003) Testing species richness estimation methods on single sample collection data using the Danish Diptera. Biodivers Conserv 12:667-686

Petersen FT, Meier R, Larsen MN (2003) Testing species richness estimation methods using museum label data on the Danish Asilidae. Biodivers Conserv 12:687-701

Platnick NI (2008) The World Spider Catalog. Version 8.5. American Museum of Natural History, New York. http://research.amnh.org/entomology/spiders/catalog/index.html. Accessed January 2008

Pocock RI (1897) On the spiders of the suborder Mygalomorphae from the Ethiopian Region, contained in the collection of the British Museum. Proc Zool Soc Lond 1879:724-774 
Pocock RI (1898a) On the Arachnida taken in the Transvaal and in Nyasaland by Mr W. L. Distant and Dr. Percy Randall. Ann Mag Nat Hist 7:308-321

Pocock RI (1898b) The Arachnida from the province of Natal, South Africa, contained in the collection of the British Museum. Ann Mag Nat Hist 7:197-226

Pocock RI (1900) Some new Arachnida from the Cape Colony. Ann Mag Nat Hist 7:316-333

Pocock RI (1901) Descriptions of some new African Arachnida. Ann Mag Nat Hist 7:284-288

Pocock RI (1902a) Descriptions of some new species of African Solifugae and Araneae. Ann Mag Nat Hist 7:6-27

Pocock RI (1902b) Some new African spiders. Ann Mag Nat Hist 7:315-530

Polis GA, Sissom WD (1990) Life history. In: Polis GA (ed) The biology of scorpions. Stanford University Press, Stanford, pp 161-223

Possingham HP, Andelman SJ, Burgman MA et al (2002) Limits to the use of threatened species lists. Trends Ecol Evol 17(11):503-507

Prendini L (2001) A review of synonyms and subspecies in the genus Opistophthalmus C. L. Koch (Scorpiones: Scorpionidae). Afr Ent 9(1):17-48

Punzo F (1998) The biology of camel-spiders (Arachnida: Solifugae). Springer, New York

Purcell WF (1902) New South African trap-door spiders of the family Ctenizidae in the collection of the South African Museum. Trans S Afr Mus 11:348-382

Purcell WF (1903a) New Arachnida collected by Mr S. C. Conwright Schreiner at Hanover, Cape Colony. Ann S Afr Mus 3:13-40

Purcell WF (1903b) New South African spiders of the families Migidae, Ctenizidae, Barychelidae, Dipluridae and Lycosidae. Ann S Afr Mus 3:69-142

Purcell WF (1904) Descriptions of new genera and species of South African spiders. Trans S Afr Philos Soc 15:115-173

Purcell WF (1908) Araneae. In: Schultze L (ed) Forschungsreise in Sudafrika 1(2). Denkschr med naturw Ges Jena 13, pp 203-246 
Raven RJ (1985) The spider infraorder Mygalomorphae (Araneae): cladistics and systematics. Bull Am Mus Nat Hist 182:1-180

Sites JW, Marshall JC (2003) Delimiting species: a Renaissance issue in systematic biology. Trends Ecol Evol 18(9):462-470

Solow AR, Mound LA, Gaston KJ (1995) Estimating the rate of synonymy. Syst Biol 44:93-96

Strand E (1906) Über einege Vogelspinnen und afrikanische Spinnen des naturhistorischen Museums zu Wiesbaden. Jahrb nassau Ver Naturk 59:1-45

Strand E (1907) Vorläufige Diagnosen afrikanischer und südamerikanischer Spinnen. Zool Anz 31:525558

Strand E (1917) Zur Kenntnis afrikanischer Arten der Aviculariiden gattungen Idiops Perty, Harpactira Auss. und Pterinochilus Poc. Jahrb nassau Ver Naturk 70:162-171

Thiele K, Yeates D (2002) Tension arises from duality at the heart of taxonomy. Nature 419:337

Tucker RWE (1917) On some South African Aviculariidae (Arachnida). Families Migidae, Ctenizidae, Diplotheleae and Dipluridae. Ann S Afr Mus 17:79-138

Tucker RWE (1920) Contributions to the South African Arachnid Fauna. II. Ann S Afr Mus 17:439-488

Ugland KI, Gray JS, Ellingson KE (2003) The species accumulation curve and estimation of species richness. J Anim Ecol 72:888-897

Valdecasas AG, Williams D, Wheeler QD (2008) 'Integrative taxonomy' then and now: response to Dayrat (2005). Biol J Linn Soc 93:211-216

Wiens JJ, Servedio MR (2000) Species delimitation in systematics: inferring diagnostic differences between species. Proc R Soc Lond B 267:631-636

Wilson EO (2004) Taxonomy as a fundamental discipline. Proc R Soc Lond B 359:739 